\title{
META-ANALYSIS OF THE HYPOCHOLESTEROLEMIC POTENTIALS OF TURMERIC (CURCUMA LONGA) IN BROILER CHICKENS
}

\author{
Ogbuewu, I. P. ${ }^{*}$ - Mbajiorgu, C. A. \\ Department of Agriculture and Animal Health, University of South Africa, Florida Science \\ Campus, Johannesburg, South Africa \\ *Corresponding author \\ e-mail:dr.ogbuewu@gmail.com \\ (Received $12^{\text {th }}$ May 2020; accepted $16^{\text {th }}$ Sep 2020)
}

\begin{abstract}
The purpose of this experiment was to use a meta-analysis approach to resolve conflict, identify knowledge gap and develop new insights on the effect of turmeric on plasma total cholesterol (TC), high-density lipoprotein cholesterol (HDL-c) and low-density lipoprotein cholesterol (LDL-c) concentrations in broiler chickens. The authors found 64 studies following a systematic search conducted in 3 electronic databases and the World Wide Web using several search queries. Eighteen out of the 64 publications met the predefined eligibility criteria to assess the impact of turmeric on plasma TC, HDL-c and LDL-c concentrations in broiler chickens. Data collected were analysed in OpenMEE software and pooled estimation revealed that turmeric-based diets significantly reduced the concentrations of TC and LDL-c $(\mathrm{p}<0.01)$, and improved the concentrations of HDL-c $(\mathrm{p}<0.01)$ in chicken blood when compared to those on the control diets. Sub-analysis found significant associations between covariates (chicken strain, supplementation level, number of birds per treatment and duration of supplementation) and measured outcomes (TC, HDL-c and LDL-c). Significant heterogeneity $\left(I^{2}\right)$ existed in the meta-analysis, and meta-regression analysis found that chicken strain and duration of supplementation were predictors of HDL-c and LDL-c, and explained $72 \%$ of the sources of heterogeneity among the studies used in the meta-analysis. The results of the present meta-analysis showed the potential of turmeric-based diets to modulate the production of blood cholesterol in broiler chickens.
\end{abstract}

Keywords: turmeric, meat-typed broilers, cholesterol, data synthesis, meta-regression, funnel plot

\section{Introduction}

Currently, herbs and spices such as ginger, garlic and turmeric are receiving attention in chicken production because of their positive health benefits. Turmeric (Curcuma longa L.), a member of Zingiberaceae family is used in preparations of human foods and native medicines. It is low in macro-nutrients, moderate in fibre and rich in essential oils. Turmeric is a potent source of curcuminoids and possesses antioxidative, antiinflammatory, antihepatotoxic and anticarcinogenic properties and may be used as a phytoadditive in animal feed. The beneficial effects of turmeric in chickens include improvement of immune response, reduction of negative effects of heat stress via several mechanisms, enhancement of antioxidant activity, reduction in the number of harmful microbes in the gut, and improvement of blood indices which are linked to its rich phytochemicals (Jurenka, 2009; Rahimi and Kazemi-Oskuee, 2014). Addition of turmeric in animal diet has been found to enhance growth performance in broiler chickens (Emadi and Kermanshahi, 2006; Adegoke et al., 2018) and improve reproductive efficiency in rabbits (Ogbuewu et al., 2017). Emadi et al. (2007) have reported low plasma LDL-c value and improved plasma HDL-c value in broiler chickens fed turmeric at $7.5 \mathrm{~g} / \mathrm{kg}$ feed. Furthermore, the incorporation of turmeric at $2 \mathrm{~g} / \mathrm{kg}$ feed lowers plasma triglyceride, TC and LDL-c concentrations in laying hens (Kermanshahi and Riasi, 2006). Others have 
reported the influence of turmeric on blood cholesterol values of broiler chickens (Akbarian et al., 2012; Alagawany, 2015; Arslan et al., 2017; Choudhury et al., 2018). However, these results were at variance with one another and the variability may depend on factors such as dietary components, inclusion rate, feeding duration, age and stocking density among others. The use meta-analysis approach to resolve conflicting results among authors have been reported (Ressing et al., 2009). Meta-analysis is an inferential statistical method that enables the results of individual studies to be pooled and quantitatively analysed to reach conclusion that ordinarily could not be drawn from individual primary studies or narrative reviews. To our knowledge, no meta-analysis has investigated the effect of turmeric on health indices of broiler chickens. Therefore, this meta-analysis aimed to determine the effect of turmeric on plasma cholesterol characteristics in broiler chickens as to aid evidence-based decision-making.

\section{Materials and Methods}

The meta-analysis was conducted in the Department of Agriculture and Animal Health, University of South Africa, Florida Science Campus, South Africa. To realize the objectives of the current research, the authors searched Scopus, Google scholar and AGORA databases and the World Wide Web for studies that investigated the effect of turmeric on plasma TC, HDL-c and LDL-c concentrations in broiler chickens using combinations of different search queries. The search terms were turmeric, broiler chickens, plasma cholesterol, serum cholesterol and blood cholesterol. The search was conducted using Boolean logic operators (AND, NOT and OR), wildcat (* or \$), alternate spellings (?) and proximity searching (“...” or “....”). Our search yielded 64 publications of which 18 met the apriori selection criteria. For an article to be included in the analysis, the experiment must have control treatment (without turmeric) and experimental treatments (with turmeric). The diet must be free of growth-promoting substances. The study is written in English and reported at least one of these outcomes (TC, LDL-c or HDL-c) in healthy chickens with their corresponding measures of dispersion such as standard deviation (SD) or standard error (SE). In a condition, where $\mathrm{SE}$ of the mean was reported instead of SD, the SD value was calculated from SE using standard method (Higgins and Deeks, 2011). Information on the surname of first author/year of publication, outcomes of interest (TC, HDL-c and LDL-c) with their corresponding SD as well as our chosen covariates (strain, supplementation level, duration of supplementation and the number of birds included in each treatment group) were extracted from each paper that fulfilled the eligibility criteria. This meta-analysis was conducted following standard protocols as described by Koricheva et al. (2013). Standardized effect sizes were estimated using standardized mean difference (SMD), and SMD was said to significant at $p<0.01$ (Koricheva et al., 2013). We employed 2 random effect model in the study with Model I being a full model:

$$
Y_{i}=\mu+T_{i}+e_{i}
$$

where,

$Y_{i}$ : Response variable (TC, LDL-c and HDL-c) for the $\mathrm{i}^{\text {th }}$ study $(\mathrm{i}=\mathrm{I}, 2, \ldots . ., \mathrm{N}), \mathrm{N}$ is the number of study included in the analysis,

$\mu$ : Overall mean,

$T_{i}$ : Treatment effect (dietary turmeric), 
$e_{i}$ : Random error associated with observation $i$.

Model II = Model I + effects for potential of between-study variance across studies:

$$
Y_{i j k l m}=\mu+T_{i}+S_{j}+D_{k}+C_{l}+B_{m}+e_{i j k l m}
$$

where,

$Y_{i j k l m}$ : Measure for the $\mathrm{i}^{\text {th }}$ study $(\mathrm{i}=\mathrm{I}, 2, \ldots ., \mathrm{N})$,

$\mu$ : Overall mean,

$S_{j}$ : Effect of $\mathrm{j}^{\text {th }}$ strain ( $\mathrm{j}=5$; Hubbard, Ross, Cobb, Arbor acre and Anak),

$D_{k}$ : Effect of $\mathrm{k}^{\text {th }}$ duration of supplementation ( $\mathrm{k}=1$ to 56 days),

$C_{l}$ : Effect of $1^{\text {th }}$ supplementation level $(1=0.2 \mathrm{~g} / \mathrm{kg}$ feed $\geq \mathrm{n} \leq 15 \mathrm{~g} / \mathrm{kg}$ feed $)$,

$B_{m}$ : Effect of $\mathrm{m}^{\text {th }}$ number of broiler chickens included in each treatment group $(\mathrm{m}=10 \geq$ $\mathrm{n} \leq 108$ ),

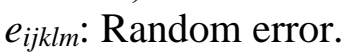

Pooled effects estimate with 95\% confidence interval (CI) for the TC, HDL-c and LDL-c were presented in forest plots using OpenMEE software (Wallace et al., 2016). Funnel plot method and Rosenberg's fail-safe number (Nfs) were used to identify the presence of publication bias. Jennions et al. (2013) have reported the robustness of meta-analysis results despite the presence of publication bias if Nfs is greater than $(5 n+10)$, where, $n=$ number of comparisons. We used Q statistics (Hedges and Olkin, 1985) and $I^{2}$ statistics (Higgins et al., 2003) to identify the presence of heterogeneity across studies, whereas sources of heterogeneity were quantified using meta-regression analysis.

\section{Results}

\section{Overview of studies included in the analysis}

Our search yielded 64 articles of which 18 papers with 2200 broiler chickens and 54 comparisons met the predefined inclusion criteria for the meta-analysis (Table 1). The articles used for the analysis span 12 years with the first study published in 2007 and the most recent published in 2018.

\section{Meta-analysis and analysis of covariates}

Pooled estimation revealed significantly $(\mathrm{p}<0.01)$ lower $\mathrm{TC}(\mathrm{SMD}=-0.332$, $I^{2}=90.74 \%$; Fig. 1 ) in broiler chickens fed turmeric diets compared to those fed control diets. In addition, statistically increased $(\mathrm{p}<0.01)$ HDL-c $\left(\mathrm{SMD}=0.581, I^{2}=90.29 \%\right.$; Fig. 2) were recorded for broiler chickens on treatment diets when compared with broiler chickens on control diets. LDL-c (SMD $=-0.331 \mathrm{mg} / \mathrm{dl}$; Fig. 3) was lower in broiler chickens fed turmeric-based diets as compared to those fed control diets, however, the difference was not significant $(\mathrm{p}>0.01)$. There was presence large heterogeneity among the studies used in the analysis as presented in Figs. 1, 2 and 3 (results from Model I). In an effort to determine the actual turmeric dose that optimizes blood cholesterol concentrations in broiler chickens, the authors chose 2 levels of supplementation (i.e. $<6 \mathrm{~g} / \mathrm{kg}$ feed and $>6 \mathrm{~g} / \mathrm{kg}$ feed) based on the mean inclusion levels reported in the studies included in the meta-analysis. The results of the effect of turmeric on plasma TC in broiler chickens are presented in Table 2. Chickens fed turmeric diet at $>6 \mathrm{~g} / \mathrm{kg}$ feed and $<6 \mathrm{~g} / \mathrm{kg}$ feed had significantly reduced TC. Similarly, there was no significant association between the plasma TC and the studied covariates. 
There was a significant relationship between TC and duration of supplementation with chickens from studies that fed turmeric for 42 days recording lower value than studies that fed turmeric for 21, 35 and 56 days.

Table 1. Studies used to evaluate the effect of turmeric on TC, HDL-c and LDL-c in broiler chickens

\begin{tabular}{|c|c|c|c|c|c|}
\hline \multirow[b]{2}{*}{ References } & \multicolumn{4}{|c|}{ Moderators } & \multirow[b]{2}{*}{ Outcomes } \\
\hline & Strain & $\mathrm{SL}(\mathrm{g} / \mathrm{kg})$ & $\begin{array}{l}\text { DOS } \\
\text { (day) }\end{array}$ & $\begin{array}{c}\text { No. of birds per } \\
\text { treatment }\end{array}$ & \\
\hline Adegoke et al 2018 & Arbor acres & $<6$ & 42 & $<46$ & TC, HDL-c \\
\hline Adegoke et al 2018 & Arbor acres & $<6$ & 42 & $<46$ & $\mathrm{TC}$ \\
\hline Hussein 2013 & Ross & $<6$ & 42 & $>46$ & $\mathrm{TC}$ \\
\hline Hussein 2013 & Ross & $>6$ & 42 & $>46$ & $\mathrm{TC}$ \\
\hline Hussein 2013 & Ross & $>6$ & 42 & $>46$ & $\mathrm{TC}$ \\
\hline Abou-Elkhair et al 2014 & Cobb & $<6$ & 35 & $<46$ & $\mathrm{TC}$ \\
\hline Fallah \& Mirzaei 2016 & Ross & $<6$ & 42 & $>46$ & TC, HDL-c, LDL-c \\
\hline Nouzarian et al 2011 & Ross & $<6$ & 42 & $>46$ & TC, HDL-c, LDL-c \\
\hline Nouzarian et al 2011 & Ross & $>6$ & 42 & $>46$ & TC, HDL-c, LDL-c \\
\hline Nouzarian et al 2011 & Ross & $>6$ & 42 & $>46$ & TC, HDL-c \\
\hline Choudhury et al 2018 & Arbor acres & $<6$ & 42 & $<46$ & TC, HDL-c \\
\hline Choudhury et al 2018 & Arbor acres & $<6$ & 42 & $<46$ & TC, HDL-c \\
\hline Choudhury et al 2018 & Arbor acres & $>6$ & 42 & $<46$ & $\mathrm{TC}$ \\
\hline Ukoha and Onunkwo 2016 & Anak & $>6$ & 56 & $<46$ & $\mathrm{TC}$ \\
\hline Ukoha and Onunkwo 2016 & Anak & $>6$ & 56 & $<46$ & $\mathrm{TC}$ \\
\hline Ukoha and Onunkwo 2016 & Anak & $>6$ & 56 & $<46$ & $\mathrm{TC}$ \\
\hline Alagawany et al 2015 & Hubbard & $<6$ & 35 & $<46$ & $\mathrm{TC}, \mathrm{LDL}$ \\
\hline Alagawany et al 2015 & Hubbard & $<6$ & 35 & $<46$ & TC, HDL-c, LDL-c \\
\hline Arslan et al 2017 & Hubbard & $<6$ & 35 & $<46$ & TC, HDL-c, LDL-c \\
\hline Arslan et al 2017 & Hubbard & $>6$ & 35 & $<46$ & TC, HDL-c, LDL-c \\
\hline Arslan et al 2017 & Hubbard & $>6$ & 35 & $<46$ & TC, HDL-c, LDL-c \\
\hline Emadi et al 2007 & Ross & $<6$ & 21 & $>46$ & TC, HDL-c, LDL-c \\
\hline Emadi et al 2007 & Ross & $<6$ & 21 & $>46$ & TC, HDL-c, LDL-c \\
\hline Emadi et al 2007 & Ross & $>6$ & 21 & $>46$ & TC, HDL-c, LDL-c \\
\hline Emadi et al 2007 & Ross & $<6$ & 35 & $>46$ & TC, HDL-c, LDL-c \\
\hline Emadi et al 2007 & Ross & $<6$ & 35 & $>46$ & TC, HDL-c \\
\hline Emadi et al 2007 & Ross & $>6$ & 35 & $>46$ & TC, HDL-c \\
\hline Emadi et al 2007 & Ross & $<6$ & 42 & $>46$ & TC, HDL-c \\
\hline Emadi et al 2007 & Ross & $<6$ & 42 & $>46$ & HDL-c \\
\hline Emadi et al 2007 & Ross & $>6$ & 42 & $>46$ & HDL-c \\
\hline Kamdev et al. 2016 & Cobb & $<6$ & 21 & $<46$ & $\mathrm{TC}$ \\
\hline Kamdev et al. 2016 & Cobb & $>6$ & 42 & $<46$ & $\mathrm{TC}$ \\
\hline Mehala \& Moorthy 2008 & Cobb & $<6$ & 42 & $<46$ & TC, HDL-c \\
\hline Mehala \& Moorthy 2008 & Cobb & $<6$ & 42 & $<46$ & TC, HDL-c \\
\hline Mehala \& Moorthy 2008 & Cobb & $<6$ & 42 & $<46$ & HDL-c \\
\hline Mehala \& Moorthy 2008 & Cobb & $<6$ & 42 & $<46$ & HDL-c \\
\hline Tirupati Reddy et.al. 2012 & Cobb & $<6$ & 42 & $<46$ & $\mathrm{TC}$ \\
\hline Tirupati Reddy et.al. 2012 & Cobb & $<6$ & 42 & $<46$ & $\mathrm{TC}$ \\
\hline Ratika et al. 2018 & Ross & $<6$ & 21 & $<46$ & $\mathrm{TC}$ \\
\hline Daneshyar et al. 2011 & Ross & $<6$ & 21 & $>46$ & TC, HDL-c, LDL-c \\
\hline Daneshyar et al. 2011 & Ross & $<6$ & 21 & $>46$ & TC, HDL-c, LDL-c \\
\hline Daneshyar et al. 2011 & Ross & $>6$ & 21 & $>46$ & TC, HDL-c, LDL-c \\
\hline Daneshyar et al. 2011 & Ross & $<6$ & 42 & $>46$ & TC, HDL-c, LDL-c \\
\hline Daneshyar et al. 2011 & Ross & $<6$ & 42 & $>46$ & TC, LDL-c \\
\hline Akbarian et al. 2012 & Ross & $<6$ & 21 & $<46$ & TC, HDL-c, LDL-c \\
\hline Al-Noori et al. 2011 & Ross & $<6$ & 42 & $<46$ & $\mathrm{TC}$ \\
\hline Al-Noori et al. 2011 & Ross & $>6$ & 42 & $<46$ & $\mathrm{TC}$ \\
\hline Saima et al. 2014 & Cobb & $<6$ & 42 & $<46$ & $\mathrm{TC}$ \\
\hline
\end{tabular}

$\mathrm{SL}=$ supplementation level, $\mathrm{DOS}=$ duration of supplementation; $\mathrm{TC}=$ total cholesterol; HDL-c $=$ high density lipoprotein cholesterol; LDL-c $=$ low density lipoprotein cholesterol 

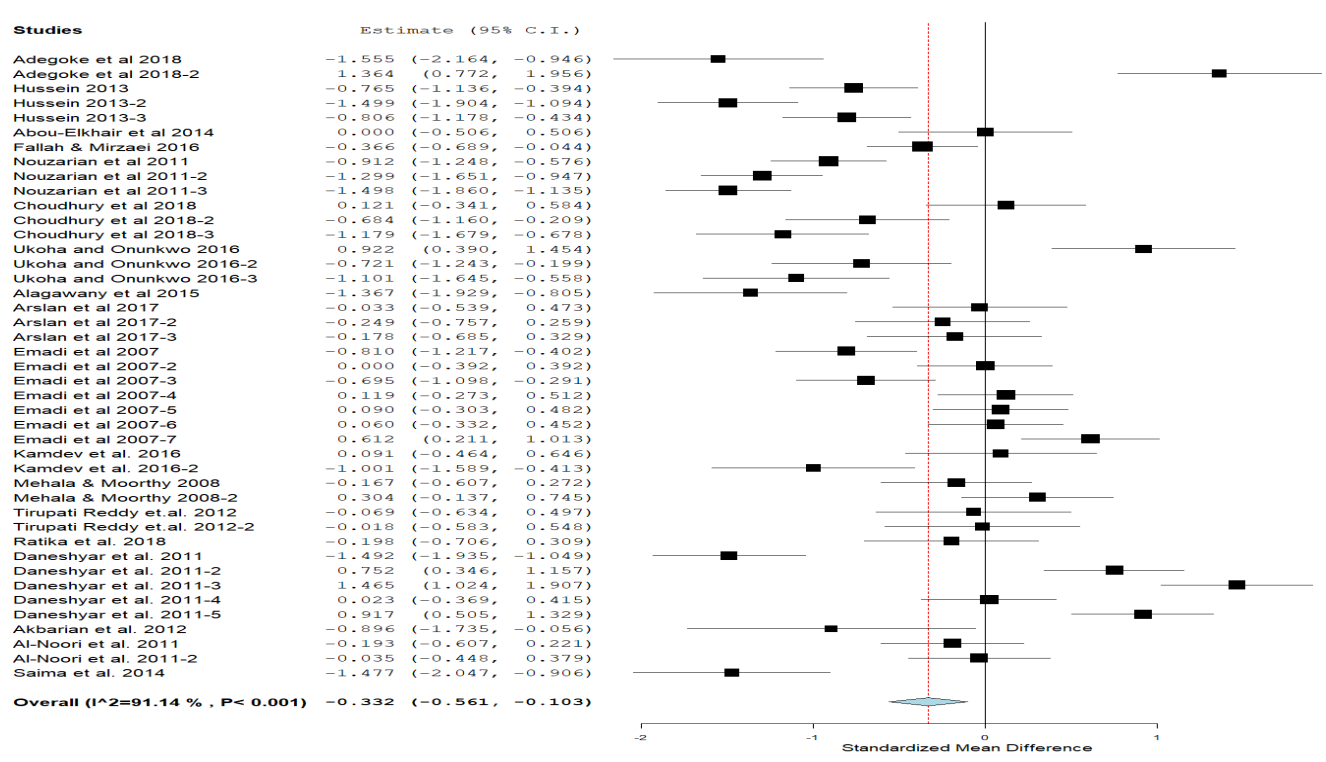

Figure 1. Forest plots of the effect of dietary turmeric supplementation on TC ( $\mathrm{mg} / \mathrm{dl})$ in broiler chickens. The solid vertical line represents the line of no effect. Points to the left of the vertical line depict a reduction in the parameter of interest and point to the right depicts an increase. Each square in the plot represents the mean effect size for the study, while the line that joined the individual square depict the lower and upper confidence interval of the effect size. The dotted line with the diamond at the base showing the 95\% CI depicts the pooled estimation. $I^{2}$ is a measure of variance above chance among studies included in the analysis. Pooled estimation is considered significant when the diamond did not touch the solid vertical line

Studies

Adegoke et al 2018 Fallah \& Mirzaei 2016 Nouzarian et al 2011 Nouzarian et al 2011-2 Nouzarian et al 2011-3 Choudhury et al 2018 Choudhury et al 2018-2 Alagawany et al 2015 Alagawany et al 2015-2 Arslan et al 2017 Arslan et al 2017-2 Arslan et al 2017-3 Emadi et al 2007 Emadi et al 2007-2 Emadi et al 2007-3

Emadi et al 2007-4 Emadi et al 2007-5 Emadi et al 2007-6 Emadi et al 2007-7 Emadi et al 2007-8 Emadi et al 2007-9 Mehala \& Moorthy 2008 Mehala \& Moorthy 2008-2 Mehala \& Moorthy 2008-3 Mehala \& Moorthy 2008-4 Daneshyar et al. 2011 Daneshyar et al. 2011-2 Daneshyar et al. 2011-3 Akbarian et al. 2012

Overall $\left(I^{\wedge} 2=90.82 \%, P<0.001\right)$
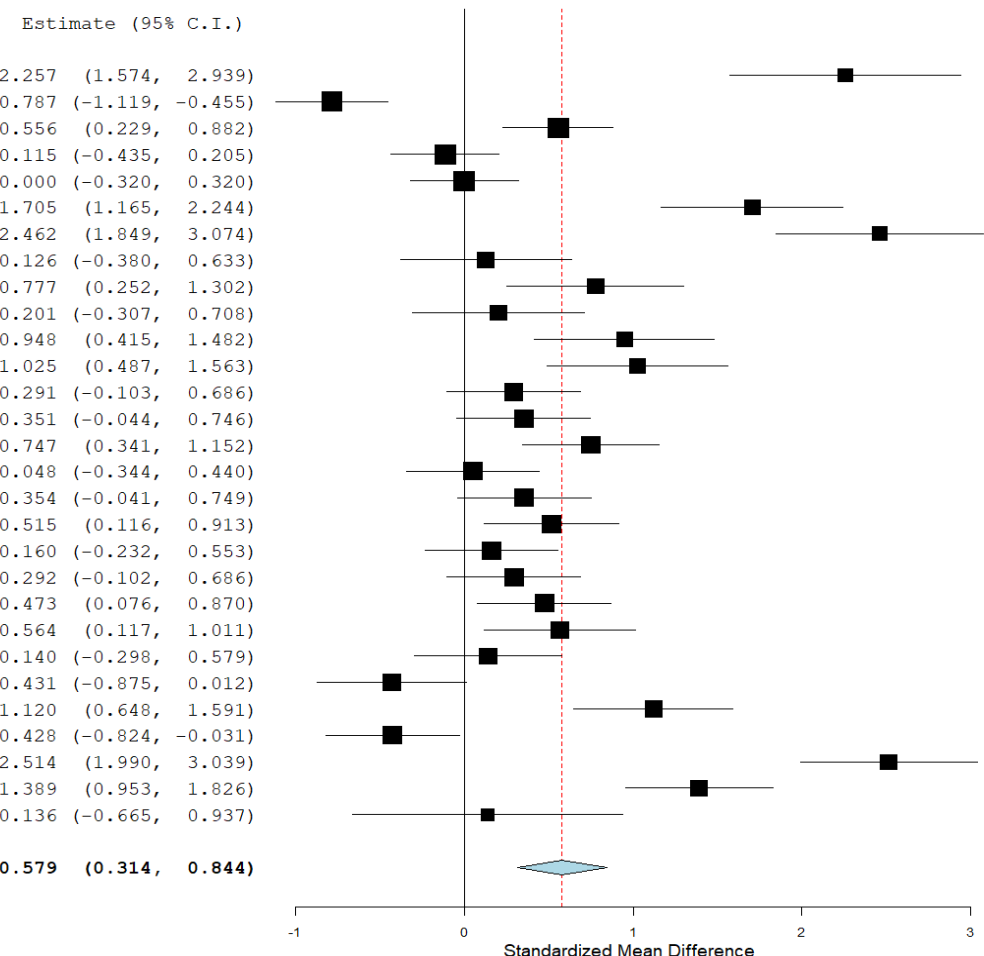

Figure 2. Forest plots of the effect of dietary turmeric supplementation on HDL-c $(\mathrm{mg} / \mathrm{dl})$ in broiler chickens 
Studies

Fallah \& Mirzaei 2016 Nouzarian et al 2011

Nouzarian et al 2011-2 Alagawany et al 2015 Alagawany et al 2015-2

Arslan et al 2017

Arstan et al 2017-2

Arslan et al 2017-3

Emadi et al 2007

Emadi et al 2007-2

Emadi et al 2007-3

Emadi et al 2007-4

Daneshyar et al. 2011

Daneshyar et al. 2011-2

Daneshyar et al. 2011-3

Daneshyar et al. 2011-4

Daneshyar et al. 2011-5

Akbarian et al. 2012

Estimate (95\% C.I.)

$-0.753(-1.084,-0.422)$

$-1.241(-1.591,-0.892)$

$0.000(-0.320,0.320)$

$-0.815(-1.342,-0.289)$

$-1.100(-1.643,-0.557)$

$-0.384(-0.895,0.127)$

$-0.944(-1.478,-0.411)$

$-0.013(-0.405,0.379)$

$-0.095(-0.487,0.297)$

$-0.818(-1.226,-0.410)$

$-0.682(-1.085,-0.278)$

$0.911(0.499,1.323)$

$1.089(0.669,1.509)$

$0.925(0.513,1.338)$

$-0.891(-1.302,-0.480)$

$-0.466(-1.277,0.345)$

Overall $\left(\left.\right|^{\wedge} 2=91.37 \%, P<0.001\right)-0.331 \quad(-0.672,0.011)$

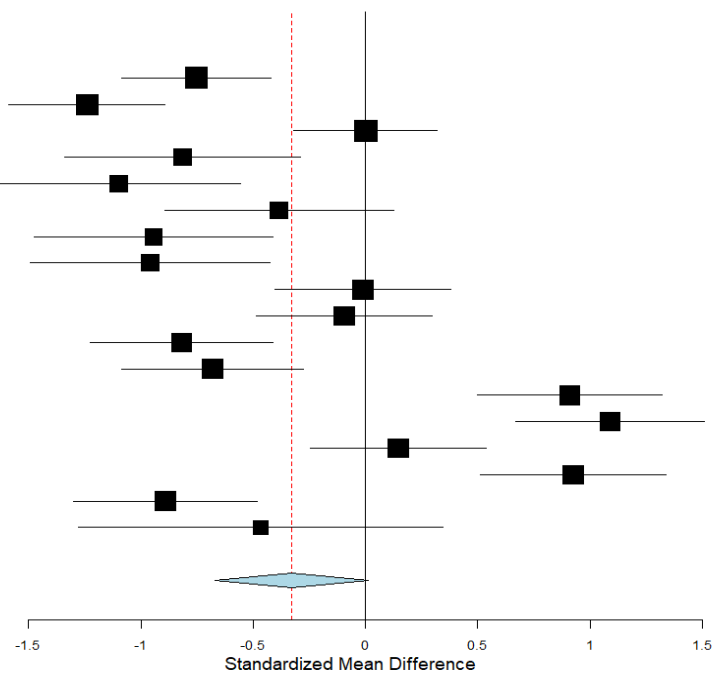

Figure 3. Forest plots of the effect of dietary turmeric supplementation on $L D L-c(m g / d l)$ in broiler chickens

Table 2. Subgroup analysis and meta-regression of effects of the moderators on TC in broiler chickens

\begin{tabular}{|c|c|c|c|c|c|c|}
\hline \multirow{2}{*}{ Covariates } & \multicolumn{3}{|c|}{ Sub group analysis } & \multicolumn{3}{|c|}{ Meta-regression } \\
\hline & SMD & $95 \% \mathrm{CI}$ & $I^{2}(\%)$ & $\mathbf{Q M}_{\mathbf{M}}$ & df & $\mathbf{R}^{2}(\%)$ \\
\hline Supplementation level & & & & 0.600 & 1 & 0.00 \\
\hline$<6 \mathrm{~g} / \mathrm{kg}$ & -0.259 & -0.514 to -0.004 & $88.27 *$ & & & \\
\hline$>6 \mathrm{~g} / \mathrm{kg}$ & -0.452 & -0.890 to -0.013 & $93.73^{*}$ & & & \\
\hline Mean & $-0.332^{*}$ & -0.561 to -0.103 & 91.14* & & & \\
\hline Duration of supplementation & & & & 1.030 & 3 & 0.00 \\
\hline $21 \mathrm{~d}$ & -0.188 & -0.800 to 0.423 & $93.70 *$ & & & \\
\hline $35 \mathrm{~d}$ & -0.168 & -0.464 to 0.128 & $69.39 *$ & & & \\
\hline $42 \mathrm{~d}$ & $-0.444 *$ & -0.758 to -0.129 & $91.85^{*}$ & & & \\
\hline $56 \mathrm{~d}$ & -0.300 & -1.512 to 0.913 & $93.57 *$ & & & \\
\hline Mean & $-0.332 *$ & -0.561 to -0.103 & $91.14 *$ & & & \\
\hline Strain of broiler used & & & & 0.149 & 4 & 0.00 \\
\hline Ross & $-0.321 *$ & -0.644 to -0.002 & $93.32 *$ & & & \\
\hline Arbor acres & -0.388 & -1.317 to 0.541 & 93.70* & & & \\
\hline Hubbard & -0.447 & -1.018 to 0.124 & $79.25^{*}$ & & & \\
\hline Cobb & -0.279 & -0.684 to 0.126 & $79.15^{*}$ & & & \\
\hline Anak & -0.300 & -1.512 to 0.913 & $93.57 *$ & & & \\
\hline Mean & $-0.332 *$ & -0.561 to -0.103 & $91.14 *$ & & & \\
\hline Number of bird / treatment & & & & 0.004 & 1 & 0.00 \\
\hline$<46$ birds & $-0.337 *$ & -0.605 to -0.068 & $84.52 *$ & & & \\
\hline$>46$ birds & -0.324 & -0.700 to 0.052 & $94.45^{*}$ & & & \\
\hline Mean & $-0.332^{*}$ & -0.561 to -0.103 & $91.14 *$ & & & \\
\hline
\end{tabular}

*Significant at $\mathrm{p}<0.01 ; \mathrm{SMD}=$ standardized mean difference; $\mathrm{CI}=$ confidence interval; $I^{2}=$ heterogeneity; $\mathrm{Q}_{\mathrm{M}}=$ moderator coefficient; $\mathrm{df}=$ degree of freedom; $\mathrm{R}^{2}=$ amount of heterogeneity accounted for

The sub-analysis of the impact of turmeric on HDL-c as illustrated in Table 3 revealed that the effect of turmeric on HDL-c was more pronounced in chickens from studies that fed turmeric at $<6 \mathrm{~g} / \mathrm{kg}$ feed than studies that fed $>6 \mathrm{~g}$ turmeric/ $\mathrm{kg}$ feed. Birds from studies that fed turmeric for 35 and 42 days had statistically increased plasma HDL-c relative to those that fed the same diet for 21 days. However, we noticed 
that effect estimation was higher in chickens from studies that fed turmeric for 42 days. Strain influenced $(\mathrm{p}<0.01)$ HDL-c with chickens from studies that used Hubbard and Arbor acres recording higher HDL-c as compared to those studies that used Ross and Cobb. Higher $(\mathrm{p}<0.01)$ HDL-c value was obtained in chickens from trials that included $<46$ birds per treatment group than trials that included $>46$ birds. The sub-analysis of the influence of covariates on plasma LDL-c as presented in Table 4 revealed that birds from studies that fed turmeric at $>6 \mathrm{~g} / \mathrm{kg}$ feed for 35 days $(\mathrm{p}<0.01)$ had statistically reduced LDL-c. Additionally, broiler chickens from trials that used Hubbard and included less than 46 birds per treatment group had significantly reduced LDL-c.

Table 3. Subgroup analysis and meta-regression of effects of the moderators on HDL-c in broiler chickens

\begin{tabular}{|c|c|c|c|c|c|c|}
\hline \multirow{2}{*}{ Covariates } & \multicolumn{3}{|c|}{ Subgroup analysis } & \multicolumn{3}{|c|}{ Meta-regression } \\
\hline & SMD & $95 \% \mathrm{CI}$ & $P^{2}(\%)$ & $\mathbf{Q M}_{\mathbf{M}}$ & df & $\mathbf{R}^{2}(\%)$ \\
\hline Supplementation level & & & & 0.037 & 1 & 0.00 \\
\hline$<6 \mathrm{~g} / \mathrm{kg}$ & $0.602 *$ & 0.245 to 0.959 & $92.72 *$ & & & \\
\hline$>6 \mathrm{~g} / \mathrm{kg}$ & $0.511 *$ & 0.206 to 0.816 & $76.97 *$ & & & \\
\hline Mean & $0.579 *$ & 0.335 to 0.827 & $90.82^{*}$ & & & \\
\hline Duration of supplementation & & & & 0.129 & 2 & 0.00 \\
\hline $21 \mathrm{~d}$ & 0.601 & -0.146 to 1.347 & $93.87^{*}$ & & & \\
\hline $35 \mathrm{~d}$ & $0.476^{*}$ & 0.225 to 0.726 & 56.48 & & & \\
\hline $42 \mathrm{~d}$ & $0.622 *$ & 0.214 to 1.030 & $93.20 *$ & & & \\
\hline Mean & $0.579 *$ & 0.314 to 0.844 & $90.82 *$ & & & \\
\hline Strain of broiler used & & & & $17.8^{*}$ & 3 & 37.35 \\
\hline Ross & 0.372 & 0.063 to 0.680 & $90.44 *$ & & & \\
\hline Arbor acres & $2.116^{*}$ & 1.644 to 2.587 & 44.50 & & & \\
\hline Hubbard & $0.608^{*}$ & 0.235 to 0.981 & 60.81 & & & \\
\hline Cobb & 0.345 & -0.290 to 0.980 & $87.44^{*}$ & & & \\
\hline Mean & $0.579 *$ & 0.314 to 0.844 & $90.82^{*}$ & & & \\
\hline No. bird / treatment & & & & 2.33 & 1 & 5.05 \\
\hline$<46$ birds & $0.837^{*}$ & 0.391 to 1.282 & $89.33^{*}$ & & & \\
\hline$>46$ birds & 0.383 & 0.065 to 0.702 & $91.03^{*}$ & & & \\
\hline Mean & $0.579 *$ & 0.314 to 0.844 & $90.82^{*}$ & & & \\
\hline
\end{tabular}

Table 4. Subgroup analysis and meta-regression of effects of the moderators on LDL-c in broiler chickens

\begin{tabular}{|c|c|c|c|c|c|c|}
\hline \multirow{2}{*}{ Covariates } & \multicolumn{3}{|c|}{ Subgroup analysis } & \multicolumn{3}{|c|}{ Meta-regression } \\
\hline & SMD & $95 \% \mathrm{CI}$ & $P^{2}(\%)$ & $\mathbf{Q M}_{\mathbf{M}}$ & df & $\mathbf{R}^{2}(\%)$ \\
\hline $\begin{array}{c}\text { Supplementation level } \\
<6 \mathrm{~g} / \mathrm{kg} \\
>6 \mathrm{~g} / \mathrm{kg} \\
\text { Mean }\end{array}$ & $\begin{array}{c}-0.071 \\
-0.842^{*} \\
-0.331 \\
\end{array}$ & $\begin{array}{c}-0.484 \text { to } 0.342 \\
-1.286 \text { to }-0.399 \\
-0.672 \text { to } 0.011 \\
\end{array}$ & $\begin{array}{l}91.04 * \\
84.29 * \\
91.37 *\end{array}$ & 5.70 & 1 & 23.53 \\
\hline $\begin{array}{l}\text { Duration of supplementation } \\
\qquad \begin{array}{c}21 \mathrm{~d} \\
35 \mathrm{~d} \\
42 \mathrm{~d} \\
\text { Mean } \\
\end{array} \\
\end{array}$ & $\begin{array}{c}0.322 \\
-0.827^{*} \\
-0.359 \\
-0.331 \\
\end{array}$ & $\begin{array}{c}-0.240 \text { to } 0.883 \\
-1.032 \text { to }-0.623 \\
-0.892 \text { to } 0.174 \\
-0.672 \text { to } 0.011 \\
\end{array}$ & $\begin{array}{c}87.10^{*} \\
0.00 \\
91.16^{*} \\
91.37^{*} \\
\end{array}$ & $9.65^{*}$ & 2 & 34.62 \\
\hline $\begin{array}{c}\text { Broiler strain used } \\
\text { Ross } \\
\text { Hubbard } \\
\text { Mean } \\
\end{array}$ & $\begin{array}{c}-0.144 \\
-0.831^{*} \\
-0.331 \\
\end{array}$ & $\begin{array}{c}-0.558 \text { to } 0.270 \\
-1.076 \text { to }-0.586 \\
-0.672 \text { to }-0.011 \\
\end{array}$ & $\begin{array}{c}92.88 * \\
6.53 \\
91.37 * \\
\end{array}$ & 3.63 & 1 & 14.20 \\
\hline $\begin{array}{c}\text { No. bird / treatment } \\
<46 \text { birds } \\
>46 \text { birds } \\
\text { Mean }\end{array}$ & $\begin{array}{c}-0.802^{*} \\
-0.122 \\
-0.331^{*}\end{array}$ & $\begin{array}{l}-1.029 \text { to }-0.574 \\
-0.555 \text { to } 0.311 \\
-0.672 \text { to }-0.011\end{array}$ & $\begin{array}{c}0.00 \\
93.46^{*} \\
91.37^{*}\end{array}$ & 3.61 & 1 & 14.15 \\
\hline
\end{tabular}




\section{Analysis of heterogeneity and publication bias}

Results of the potential causes of heterogeneity as shown in the results of Model II showed no significant association between covariates and plasma TC (Table 2). However, broiler strain $\left(\mathrm{Q}_{\mathrm{M}}=17.80, \mathrm{p}<0.01\right)$ influenced HDL-c and accounted for $37.35 \%$ of the between-study variance (Table 3), while duration of supplementation $\left(\mathrm{Q}_{\mathrm{M}}=9.65, \mathrm{p}<0.01\right)$ influenced plasma LDL-c and accounted for $34.62 \%$ of betweenstudy variance (Table 4). The funnel plots of differences in means of plasma TC, HDL$\mathrm{c}$ and LDC-c between broiler chickens fed diet with or without turmeric as displayed in Figure $4 a, b$ and $c$, respectively suggest the existence of publication bias. The Rosenberg's Nfs for the database was 565, which is more than 2 folds of the threshold of $280(5 \times \mathrm{n}=54+10)$ needed to find the mean effect size robust. Therefore, the existence of publication bias was not a serious problem in the current meta-analysis as a large number of unpublished studies would be required to alter the significant difference between the experimental and control groups.

a

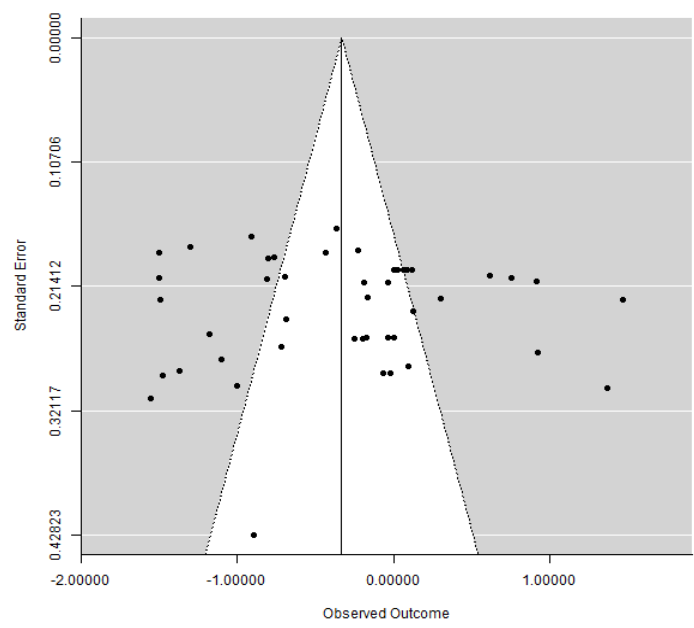

b

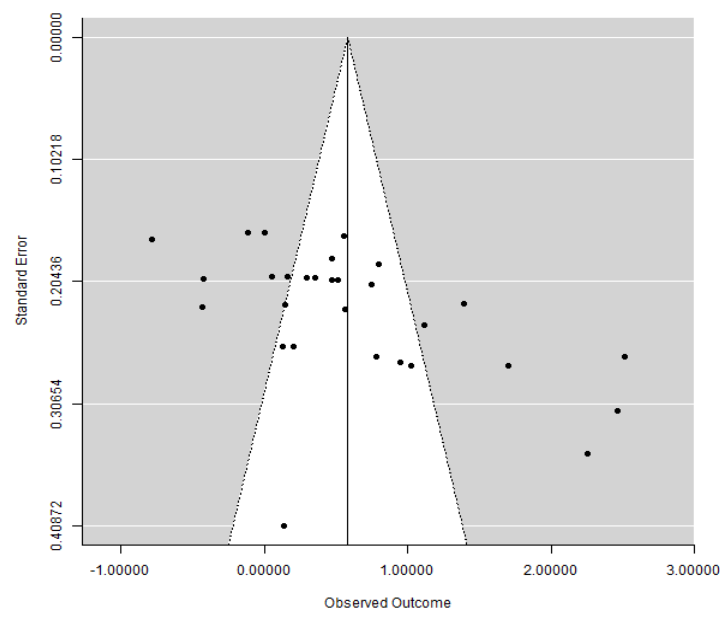

c

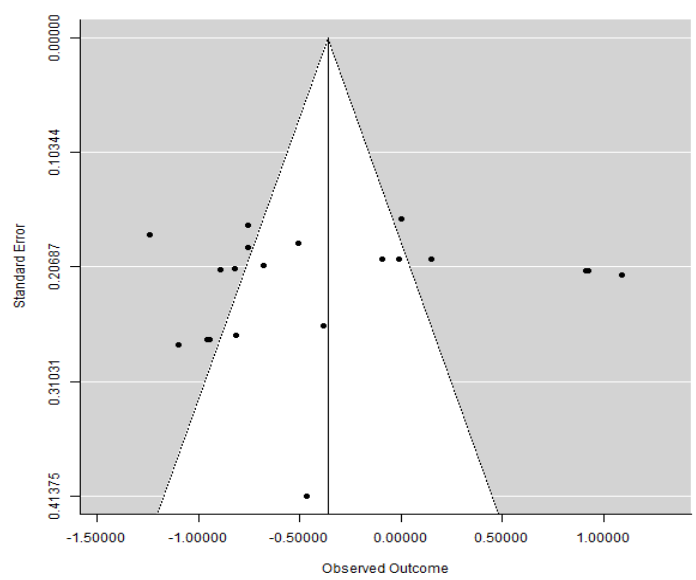

Figure 4. Funnel plots of the effect of dietary turmeric supplementation on concentrations of TC (a), HDL-c (b) and LDC-c (c) in broiler chickens 


\section{Discussion}

To our knowledge this study is the first meta-analysis that evaluated the effect of turmeric on plasma TC, LDL-c and HDL-c concentrations in broiler chickens. The main thrust of this meta-analysis was to provide evidence that turmeric improves health indices in broiler chickens. Blood biochemical components are indicators of the state of the cells, tissue and organs in farm animals (Akinfola et al., 2007). The association between blood cholesterol and nutrition in animal model has been documented (Okeudo, 2000; Iwuji et al., 2018). The finding from this meta-analysis showed that turmeric influenced plasma cholesterol characteristics in broiler chickens. This is in harmony with Kermanshahi and Riasi (2006) and Hosseini-Vashan et al. (2012) who reported significantly reduced TC and LDL-c value in broiler chickens fed turmeric supplemented diets for 42 days. More so, turmeric supplementation increased plasma HDL-c and reduced plasma TC levels which further confirm the earlier report that turmeric improve plasma HDL-c and reduce the plasma LDL-c in broiler chickens (Emadi et al., 2007). However, the result of present meta-analysis differed from Mehala and Moorthy (2008), who reported lack of significant changes in plasma TC levels of broiler chickens fed turmeric at $2 \mathrm{~g} / \mathrm{kg}$ feed. The reason for this disparity is not known, however it could be attributed to supplementation dose. The superior effect of dietary turmeric in lowering plasma TC and LDL-c concentrations in broiler chickens as seen in the present meta-analysis may be due to increased bioavailability of turmeric bioactive compounds thus inhibiting the production of hepatic 3-hydroxyl-3-methyglutaryl-CoA reductase and cholesterol $7 \alpha$-hydroxylase by up-regulation of ATP-binding cassette transporter A1 in foam cells in broiler chickens fed turmeric.

Birds fed turmeric $>6 \mathrm{~g} / \mathrm{kg}$ feed had reduced TC and LDL-c than birds fed the same diet at $<6 \mathrm{~g} / \mathrm{kg}$ feed, but birds fed turmeric at $<6 \mathrm{~g} / \mathrm{kg}$ feed had better HDL-c. This systematic review has shown the effectiveness of turmeric diet at a level more than 6 $\mathrm{g} / \mathrm{kg}$ feed in lowering plasma TC and LDL-c concentrations in broiler chickens. Importantly, birds from studies that fed less or more than $6 \mathrm{~g}$ turmeric/kg feed had better HDL-c value. However, the effect was more pronounced in studies that fed turmeric at $>6 \mathrm{~g} / \mathrm{kg}$ feed. The reason for the disparity is not known, however, it is likely that blood cholesterol parameters require different dietary levels and nutrient components for its production in the liver. This observation is in line with the earlier results of others (Ogbuewu and Mbajiorgu, 2019; Modisaojang-Mojanaja et al., 2019) who reported that dietary nutrient requirements for optimizing different blood components in animal model are dynamic. However, it is advised that more research be conducted to determine the exact amount of turmeric required to optimize the different blood cholesterol components in broiler chickens using a quadratic optimization model. Birds from studies that fed turmeric for 35 days had significantly reduced LDL-c, whereas birds from studies that fed turmeric for 21 and 42 days had comparable LDL-c concentrations. Conversely, birds from trials that fed turmeric for 35 and 42 days had significantly better HDL-c compared to birds from the experiment that fed the same ration for 21 days. The plasma TC levels were significantly reduced in birds fed turmeric for 35 days relative to those on the other 3 supplementation durations. The superior plasma cholesterol values of broiler chickens on turmeric intervention for 35 and 42 days as compared to those on turmeric intervention for 21 and 56 days is an indication that impact of turmeric in blood cholesterol levels of broiler chickens may be dependent on duration feeding. Thus for improved blood cholesterol production in broiler chickens, turmeric-based diets should be fed between 35 and 42 days. The 
present meta-analysis showed that broilers from Hubbard strains had significantly reduced plasma LDL-c, while those from Hubbard and Arbor acres strains had significantly better plasma HDL-c compared to broiler chickens from the other three strains (Ross, Cobb and Anak). The physiological explanation for this discrepancy is not fully known. However, it may be partially attributed to genetic variations among the different broiler strains included in the meta-analysis (Acar et al., 1991). Results also showed that number of broilers included in each treatment affected plasma cholesterol concentration with those from studies that included less than 46 birds per treatment having significantly better LDL-c and HDL-c than broilers from studies that included more than 46 broiler chickens. The observed poor blood cholesterol levels recorded in broiler chickens from trials that included more than 46 chickens per treatment could be explained in part to overcrowding stress which has been established to negatively affect the biochemical and physiological parameters in broiler chickens (Thaxton et al., 2005; Guardia et al., 2011).

Heterogeneity and publication bias exist in the current meta-analysis. This was envisaged as studies used for the analysis were drawn from different part of the globe. Meta-regression of the moderators that may act as effect modifiers (i.e. chicken strain, supplementation level, duration of supplementation and number of broilers included in each treatment) accounted for most of the heterogeneity. Furthermore, we observed that duration of supplementation and chicken strain are significant predictors of plasma LDL-c and serum HDL-c, respectively in broiler chickens, and explained $72 \%$ of the heterogeneity among studies included the analysis. Funnel plots suggest the existence of publication bias and the Rosenberg's Nfs for the database is 565, which is more than 2 folds of the threshold of $280(5 \times \mathrm{n}=54+10)$ needed to find the mean effect size robust. However, Jennions et al. (2013) have reported that meta-analysis results can still be robust in the presence of publication bias provided $\mathrm{Nfs}$ is greater than $(5 n+10)$. Thus, the existence of publication bias was not an issue in the current meta-analysis as large number of unpublished studies would be required to alter the significant difference found between the mean effect size of birds in experimental and control groups.

\section{Conclusion}

The findings of this meta-analysis revealed that dietary turmeric supplementation improved plasma cholesterol values in broiler chickens. However, sub-analysis results indicated that dietary turmeric supplementation at a rate less than $6 \mathrm{~g} / \mathrm{kg}$ feed or more than $6 \mathrm{~g} / \mathrm{kg}$ feed reduced plasma TC concentration. Broiler chickens fed diet supplemented with turmeric at a rate more than $6 \mathrm{~g} / \mathrm{kg}$ feed, on the other hand, reduced the concentrations of LDL-c in broiler chickens. Dietary turmeric supplementation improved plasma HDL-c; however, the effect was higher in the group that received turmeric at a rate more than $6 \mathrm{~g} / \mathrm{kg}$ feed. Meta-regression analysis revealed significant associations between covariates (duration of supplementation and chicken strain) and outcomes of interest (LDL-c and HDL-c) and explained $72 \%$ of the sources of heterogeneity among the studies included in the meta-analysis. It is concluded that turmeric supplementation to the rations of broiler chickens is desirable, mainly due to its beneficial influences on blood TC, LDL-c and HDL-c. However, more studies are needed to ascertain the exact turmeric supplementation dose that optimize blood TC, LDL-c and HDL-c in broiler chickens. 


\section{REFERENCES}

[1] Abou-Elkhair, R., Ahmed, H. A., Selim, S. (2014): Effects of black pepper (Piper nigrum), turmeric powder (Curcuma longa) and coriander seeds (Coriandrum sativum) and their combinations as feed additives on growth performance, carcass traits, some blood parameters and humoral immune response of broiler chickens. - AsianAustralasian Journal of Animal Science 27: 847-854.

[2] Acar, N., Moran, E. T. Jr., Bligili, S. F. (1991): Live performance and carcass yield of male broilers from two commercial strain crosses receiving rations containing lysine below and above the established requirement between six and eight weeks of age. Poultry Science 70: 2315-2321.

[3] Adegoke, A. V., Abimbola, M. A., Sanwo, K. A., Egbeyale, L. T., Abiona, J. A., Oso, A. O., Iposu, S. O. (2018): Performance and blood biochemistry profile of broiler chickens fed dietary turmeric (Curcuma longa) powder and cayenne pepper (Capsicum frutescens) powders as antioxidants. - Veterinary and Animal Science 6: 95-102.

[4] Akbarian, A., Golian, A., Kermanshahi, H., Gilani, A., Moradi, S. (2012): Influence of turmeric rhizome and black pepper on blood constituents and performance of broiler chickens. - African Journal of Biotechnology 11: 8606-8611.

[5] Akinfola, E. O., Matanmi, O., Fatufe, A. A. (2007): Effect of residual cyanogenic glycosides in cassava based diets on serum metabolites of cockerel chicks. - Proceedings of Annual Conference Nigerian Society for Animal Production, pp: 105-107.

[6] Alagawany, M. M. (2015): Nutritional and biological effects of turmeric (Curcuma longa) supplementation on performance, serum biochemical parameters and oxidative status of broiler chicks exposed to endosulfan in the diets. - Asian Journal of Animal and Veterinary Advances 10: 86-96.

[7] Al-Noori, M. A., Hossain, A. B., AI-Maahidy, A. H. A., Th, S., AI-Rawi, J. (2011): The effect of dietary Curcuma longa powder supplementation on some blood parameters and carcass traits of broiler chickens. - Al-Anbar Journal of Veterinary Sciences 4: 69-74.

[8] Arslan, M., Haq, A., Ashraf, M., Iqbal, J., Mund, M. D. (2017): Effect of turmeric (Curcuma longa) supplementation on growth performance, immune response, carcass characteristics and cholesterol profile in broilers. - Veterinaria 66: 16-20.

[9] Choudhury, D., Mahanta, J., Sapcota, D., Saikia, B., Islam, R. (2018): Effect of dietary supplementation of turmeric (Curcuma longa) powder on the performance of commercial broiler chicken. - International Jounal of Livestock Research 8: 182-191.

[10] Daneshyar, M., Alizadeh, G. M., Sabzi, B. F., Farhangpajhoh, F., Aghaei, M. (2011): Effects of dietary turmeric supplementation on plasma lipoproteins, meat quality and fatty acid composition in broilers. - South African Journal of Animal Sciences 41: 420-428.

[11] Emadi, M., Kermanshahi, H. (2006): Effect of turmeric rhizome powder on performance and carcass characteristics of broiler chickens. - International Journal of Poultry Sciences 5: 1069-1072.

[12] Emadi, M., Kermanshahi, H., Maroufyan, E. (2007): Effect of varying levels of turmeric rhizome powder on some blood parameters of broiler chickens fed corn-soybean meal based diets. - International Journal of Poultry Sciences 6: 345-348.

[13] Fallah, R., Mirzaei, E. (2016): Effect of dietary inclusion of turmeric and thyme powders on performance, blood parameters and immune system of broiler chickens. - Journal of Livestock Sciences 7: 180-186.

[14] Guardia, S., Konsak, B., Combes, S., Levenez, F., Cauquil, L., Guillot, J. F., MoreauVauzelle, C., Lessire, M., Juin, H., Gabriel, I. (2011): Effects of stocking density on the growth performance and digestive microbiota of broiler chickens. - Poultry Science 90: 1878-1889.

[15] Hedges, L. V., Olkin, I. (1985): Statistical Methods for Meta-Analysis. - Academic Press, San Diego, CA, USA. 
[16] Higgins, J., Thompson, S. G., Deeks, J. J., Altman, D. G. (2003): Measuring inconsistency in meta-analyses. - British Medical Journal 327: 557-560.

[17] Higgins, J. P. T., Deeks, J. J. (2011): Chapter 7: Selecting studies and collecting data. In: Higgins, J. P., Green, S. (eds.) Cochrane Handbook for Systematic Reviews of nterventions Version 5.1.0 (updated March 2011). The Cochrane Collaboration, 2011. Available from http://handbook.cochrane.org/ (Accessed: 28th April, 2020).

[18] Hosseini-Vashan, S. J., Golian, A., Yaghobfar, A., Zarban, A., Afzali, N., Esmaeilinasab, P. (2012): Antioxidant status, immune system, blood metabolites and carcass characteristic of broiler chickens fed turmeric rhizome powder under heat stress. African Journal of Biotechnology 11: 16118-16125.

[19] Hussein, S. N. (2013): Effect of turmeric (Curcuma longa) powder on growth performance, carcass traits, meat quality, and serum biochemical parameters in broilers. Journal of Advanced Biomedicine and Pathobiology Research 3: 25-32.

[20] Iwuji, T. C., Ogbuewu, I. P., Herbert, U. (2018): Haematology and serum biochemistry of growing New Zealand white (NZW) rabbits administered Panax ginseng extracts. Comparative Clinical Pathology 27: 1691-1697.

[21] Jennions, M. D., Lortie, C. J., Rosenberg, M. S., Rothstein, H. R. (2013): Chapter 14: Publication and related bias. - In: Koricheva, J., Gurevitch, J., Mengersen, K. (eds.) Handbook of meta-analysis in Ecology and Evolution. - Princeton University Press, Princeton and London, pp. 207-236.

[22] Jurenka, J. S. (2009): Anti-inflammatory properties of curcumin, a major constituent of Curcuma longa: a review of preclinical and clinical research. - Altern Medicine Rev 14: 141-153.

[23] Kamdev, S., Swain, P., Behera, K., Nayak, S. M., Barik, S. R., Patro, P., Meher, P. (2016): Effect of turmeric (Curcuma Longa) supplementation on growth and blood chemistry of broilers. - Explor Animal Medical Research 6: 75-79.

[24] Kermanshahi, H., Riasi, A. (2006): Effect of turmeric rhizome powder (Curcuma longa) and soluble NSP degrading enzyme on some blood parameters of laying hens. International Journal of Poultry Science 5: 494-498.

[25] Koricheva, J., Gurevitch, J., Mengersen, K. (2013): Handbook of meta-analysis in ecology and evolution. - Princeton University Press, Princeton and Oxford.

[26] Mehala, C., Moorthy, M. (2008): Production performance of broilers fed with Aloe vera and Curcuma longa (Turmeric). - International Journal of Poultry Science 7: 852-856.

[27] Modisaojang-Mojanaja, M. M. C., Ogbuewu, I. P., Oguttu, J. W., Mbajiorgu, C. A. (2019): Moderate levels of dietary Moringa oleifera leaf meal supplementation improve blood values in broiler chickens. - Journal of Agriculture Food and Environment 17: 3944.

[28] Nouzarian, R., Tabeidianlo, S. A., Toghyani, M., Ghalamkari, G., Toghyani, M. (2011): Effect of turmeric powder on performance, carcass traits, humoral immune responses, and serum metabolites in broiler chickens. - Journal of Animal and Feed Sciences 20: 389400 .

[29] Ogbuewu, I. P., Okehi, M. C., Jiwuba, P. C. (2017): Effect of phytobiotic (turmeric) supplementation on semen and blood characteristics of rabbits. - Comparative Clinical Pathology 26: 817-822.

[30] Ogbuewu, I. P., Mbajiorgu, C. A. (2019): Supplementation and optimization of ginger (Zingiber officinale) rhizome powder in growing rabbit diets. - Indian Journal of Animal Research, doi: 10.18805/ijar.B-101.

[31] Okeudo, N. J. (2000): Introductory biochemistry, 1st edition. - T'Afrique International Associate Publication, Owerri.

[32] Rahimi, H. R., Kazemi-Oskuee, R. (2014): Curcumin from traditional Iranian medicine to molecular medicine. - Razavi Int Journal of Medicine 2: 3-4.

[33] Ratika, K., Singh, R. K. J., Singh, R. K., Singh, M. (2018): Weekly assessment of growth performance of broilers fed diet supplemented with garlic and turmeric powder and their 
combination. - International Journal of Current Microbiology and Applied Science 7: 1373-1381.

[34] Ressing, M., Blettner, M., Klug, S. J. (2009): Systematic literature reviews and metaanalyses: Part 6 of a series on evaluation of scientific publications. - Dtsch Arztebl Int 106: 456-463.

[35] Saima, A., Mukhtar, M., Manzoor, S., Hssain, Z., Ali, A., Tabassum, R., Imran, M., Amer, M. Y., Bhatti, N. (2014): Effect of garlic, black seed and turmeric on the growth of broiler chicken. - Pakistan Journal Nutrition 13: 204-210.

[36] Thaxton, J. P., Olanrewaju, H. A., Branton, S. L., Roush, W. B. (2005): Stocking density effects on male broilers grown to 1.8 kilograms of body weight. - Poultry Science 708 : 344-351.

[37] Tirupati, E. R., Sudhakara, P. R., Satyanarayana, R. P. V. V., Shakila, S. (2012): Effect of herbal preparations (Phyllanthus emblica, Curcuma longa and Ocimum sanctum) on the performance of broilers. - Tamil-Nadu Journal of Veternary and Animal Sciences 8: 209214.

[38] Ukoha, O. A., Onunkwo, D. N. (2016): The effect of turmeric (Curcuma longa) on growth performance of broiler chickens. - International Research Journal of Agriculture and Aquatic Science 3: 131-135.

[39] Wallace, B. C., Lajeunesse, M. J., Dietz, G., Dahabreh, I. J., Trikalinos, T. A., Schmid, C. H., Gurevitch, J. (2016): OpenMEE: intuitive, open-source software for meta-analysis in ecology and evolutionary biology. - Methods Ecology and Evolution 8: 941-947. 